\title{
Increased Rotavirus Prevalence in Diarrheal Outbreak Precipitated by Localized Flooding, Solomon Islands, 2014
}

\author{
Forrest K. Jones, Albert I. Ko, Chris Becha, \\ Cynthia Joshua, Jennie Musto, Sarah Thomas, \\ Axelle Ronsse, Carl D. Kirkwood, Alison Sio, \\ Audrey Aumua, Eric J. Nilles
}

Flooding on 1 of the Solomon Islands precipitated a nationwide epidemic of diarrhea that spread to regions unaffected by flooding and caused $>6,000$ cases and 27 deaths. Rotavirus was identified in $38 \%$ of case-patients tested in the city with the most flooding. Outbreak potential related to weather reinforces the need for global rotavirus vaccination.

$\mathrm{P}$ acific Island nations are vulnerable to extreme weather events that are projected to increase in severity and frequency with global climate change and can be associated with substantial health impacts, including outbreaks of diarrheal illness and other diseases (1-4). During the first week of April 2014, a tropical depression caused extensive flooding in the city of Honiara (population 64,609, 2009 census) and the surrounding province of Guadalcanal (population 158,222). Honiara is the capital city of the island nation of the Solomon Islands (population 515,870), a nation which consists of 9 provinces and 992 islands in the Western Pacific (Figure 1, panel A). The flooding displaced $>10,000$ residents into emergency evacuation shelters and caused 22 deaths by drowning and other injuries (5). On April 20, 2014, an outbreak of diarrhea was declared in Honiara (Figure 1, panel B). During the next 2 months, diarrhea outbreaks and diarrhea-related deaths were reported from multiple provinces across the country that were not affected by the flooding. We investigated and report the flood-related outbreak of diarrhea in Honiara and its subsequent nationwide spread.

Author affiliations: Yale School of Public Health, New Haven, Connecticut, USA (F.K. Jones, A.I. Ko); Fundação Oswaldo Cruz, Salvador, Brazil (A.I. Ko); Solomon Islands Ministry of Health and Medical Services, Honiara, Solomon Islands (C. Becha, C. Joshua, A. Sio); World Health Organization, Honiara (C. Joshua, J. Musto, A. Aumua); World Health Organization, Suva, Fiji (J. Musto, A. Ronsse, E.J. Nilles); Murdoch Childrens Research Institute, Royal Children's Hospital, Parkville, Victoria, Australia (S. Thomas, C.D. Kirkwood); La Trobe University, Melbourne, Victoria, Australia. (C.D. Kirkwood)

DOI: http://dx.doi.org/10.3201/eid2205.151743
The Study

During March 31-April 6, 2014, in Honiara, a tropical depression caused $663 \mathrm{~mm}$ of rainfall, 10 times the mean weekly rainfall recorded during 2010-2013 (6). After the flooding event, use of the Pacific Syndromic Surveillance System (PSSS) (7), which collects weekly aggregated data on diarrhea and other syndromes from 4 health facilities in Honiara and 4 provincial hospitals, was transitioned to a postdisaster Early Warning Alert and Response Surveillance Network (EWARN) to enhance outbreak detection and response (8).

To characterize the outbreak, we identified nonbloody ( $>2$ loose bowel movements in 24 hours) and bloody (any episode of loose bowel movement with visible blood) diarrhea from PSSS/EWARN databases and patient registries of 10 outpatient and inpatient facilities in Honiara and 6 provincial hospitals from the outbreak period, April 7-July 13,2014 . To verify that this was an outbreak and not normal seasonal fluctuation, we also reviewed longitudinal diarrhea data from PSSS sentinel sites during January 2013August 2015.

The National Referral Hospital (NRH) in Honiara evaluated fecal samples from inpatients and outpatients who had diarrheal illness. Samples were routinely tested for Salmonella enterica, Shigella spp, Vibrio cholerae, and rotavirus. A rapid diagnostic test (RDT), the SD BIOLINE Rota/Adeno Rapid kit (Standard Diagnostics, Inc., Yongin, South Korea), was used to test for rotavirus at the NRH (9). We genotyped rotavirus-positive samples as previously described (10) and calculated incidence rates using the Solomon Islands' 2009 census. Negative binomial regressions and Fisher exact testing evaluated differences in rates and proportions testing positive.

We identified 4,087 diarrhea cases from the city of Honiara during the outbreak period, of which 3,664 cases $(90 \%)$ were nonbloody. The mean number of weekly cases of diarrhea among PSSS sites in Honiara increased from 81.7 to 236.5 (rate ratio $2.90,95 \%$ CI $2.13-3.96$ ) from baseline to outbreak and baseline periods. (Table $1)$. The highest attack rate during the outbreak occurred in the $<5$ years age group $(32 \%)$, which was $>14 \times$ that observed for the $\geq 5$ years age group $(2 \%)$. During the outbreak, 6 of 9 provinces in the Solomon Islands reported diarrhea outbreaks, comprising the flood-affected province of Guadalcanal and 5 provinces that were not 

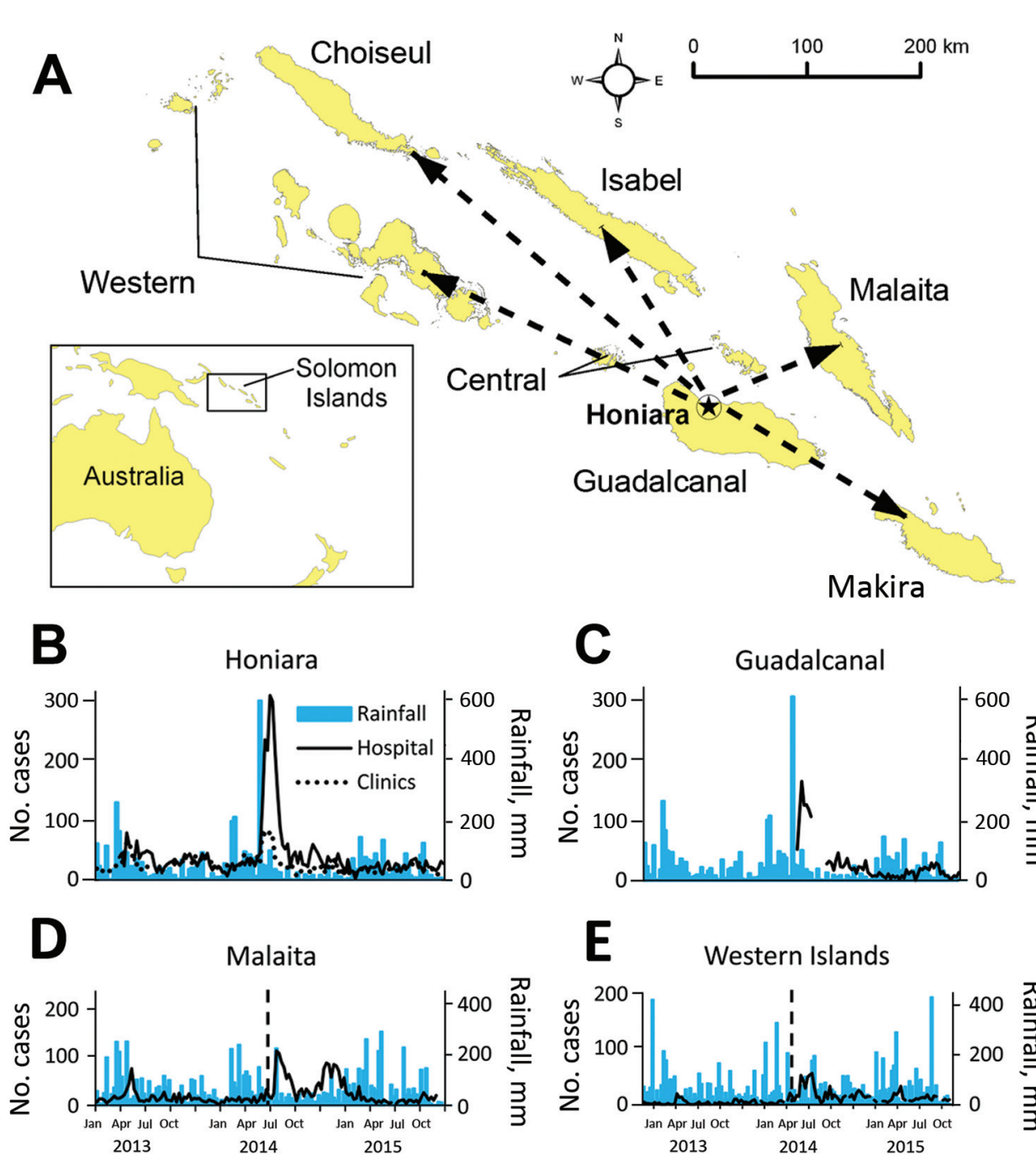

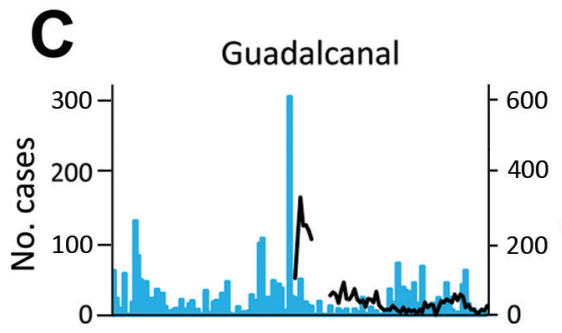

Figure 1. A) Spread of diarrheal disease in Solomon Islands after a postflooding outbreak in the capital city of Honiara, 2014, that resulted from a tropical depression. Dashed arrows indicate islands not affected by flooding where diarrheal outbreaks occurred. Two remote provinces, Temotu and Renell \& Bellona, that did not report outbreaks are not included. B-E) Weekly rainfall measurements and outpatient diarrhea cases identified from the Pacific Syndromic Surveillance System (PSSS) database, December 31, 2012-August 30, 2015. The flooding occurred during April 3-5 in B) Honiara and C) other parts of Guadalcanal; vertical lines in panels $D$ and $E$ indicate the timing of the $>$ outbreak peak in Honiara and ڤ. Guadalcanal. Cases of diarrhea are from PSSS weekly counts; Good Samaritan Hospital in Guadalcanal was designated as a PSSS site immediately postflood. Outpatient clinics in Honiara were Rove Clinic, Kukum Clinic, and Mataniko

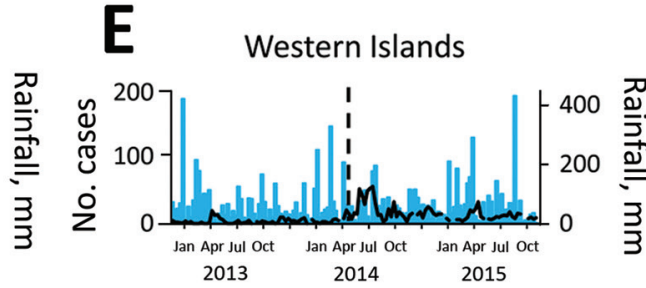
Clinic. Rainfall data presented for Guadalcanal Province is from Honiara. affected by the tropical depression and flooding (Malaita, Makira, Western, Isabel, and Choiseul) (Figure 1, panels C-E). Hospital-based surveillance identified 4,407 diarrhea cases, of which $1,626(37 \%)$ were reported from provinces unaffected by flooding. During the outbreak, 27 diarrhea-related deaths were identified, including 10 from flood-affected provinces (3.6 deaths/1,000 case-patients) and 17 from provinces where no flooding occurred (8.6 deaths/1,000 case-patients). Of the 23 deaths with information on age, $21(91 \%)$ were $<5$ years.

Among 61 fecal samples collected during the outbreak in Honiara, 23 (38\%) tested positive in the rotavirus RDT, versus none of the 43 samples collected during the same period in $2013(\mathrm{p}<0.001)$ (Table 2$)$; the proportion positive for other pathogens tested was similar for 2013 versus 2014. Of 5 samples collected in June during the outbreaks in non-flood-affected areas, 4 tested positive in the rotavirus RDT; each of the 4 positive samples were obtained from a different province (Choiseul, Isabel, Ma- kira, and Malaita). Isolates from the 4 samples were identified as genotype G9P [8] and found to have identical VP4 and VP7 sequences (GenBank accession nos. KU312099KU312102). Samples were not available for genotyping from flood-affected areas. The VP7 isolates were most similar to strains circulating in China and Russia during 2011-2013 (Figure 2).

\section{Conclusions}

We report a nationwide epidemic of diarrhea in the Solomon Islands, which was precipitated by a focal extreme weather event. Disasters can facilitate transmission of infectious diseases through population displacement, overcrowding, limited access to clean water, and compromised hygiene and sanitation (3). An assessment to quantify the risk for disease outbreaks was done immediately after the floods and identified a high risk for diarrheal outbreaks in Honiara and Guadalcanal (E.J. Nilles, unpub. data). Using protocols developed after a tsunami 
Rotavirus Prevalence, Solomon Islands

Table 1. Comparison of diarrhea case counts before, during, and after outbreak linked to localized flooding, Solomon Islands, 2013-2015*

\begin{tabular}{|c|c|c|c|c|c|c|}
\hline \multirow[b]{2}{*}{ Facility† } & \multirow[b]{2}{*}{ Facility type } & \multirow[b]{2}{*}{ Location $\ddagger$} & \multicolumn{3}{|c|}{ No. cases (mean weekly cases) } & \multirow[b]{2}{*}{ Rate ratio $(95 \% \mathrm{Cl})$} \\
\hline & & & $2013 \S$ & $2014 \pi$ & 2015\# & \\
\hline National Referral Hospital & Hospital & Honiara & $470(36.2)$ & $1969(140.6)$ & $347(24.8)$ & $4.65(3.24-6.75)$ \\
\hline Kukum & Clinic & Honiara & $290(20.7)$ & $675(48.2)$ & $256(18.3)$ & $2.47(1.67-3.70)$ \\
\hline Rove & Clinic & Honiara & $288(20.6)$ & $487(34.8)$ & $264(18.9)$ & $1.76(1.18-2.66)$ \\
\hline Good Samaritan Hospital & Hospital & Guadalcanal & NA & $812(116.0)$ & $253(18.1)$ & $6.41(4.43-9.42)$ \\
\hline Kilu'ufi & Hospital & Malaita & $248(17.7)$ & 627( & $112(8.6)$ & $3.36(2.17-5.29)$ \\
\hline Taro & Hospital & Choiseul & $4(0.3)$ & 48 & $31(2.2)$ & $3-6.71)$ \\
\hline Gizo & Hospital & Western & $72(5.1)$ & $427(30.5)$ & $140(10.8)$ & $3.88(2.37-6.52)$ \\
\hline \multicolumn{7}{|c|}{$\begin{array}{l}\text { *Source: Pacific Syndromic Surveillance System (PSSS) database. The rate ratio was calculated by comparing rates during the outbreak in } 2014 \text { and } \\
\text { rates during years without outbreaks ( } 2013 \text { and } 2015) \text { and using a negative binomial regression. NA, not available. } \\
\text { tOne PSSS site in Honiara, Mataniko Clinic, is not shown because the clinic was partially destroyed by the flood and was not operational during the peak } \\
\text { of the outbreak. } \\
\text { †The city of Honiara is the capital of the Solomon Islands and is located in Guadalcanal Province; the remaining locations are provinces of the Solomon } \\
\text { Islands. } \\
\text { \$April 8-July 14, } 2013 \text { (14 weeks). } \\
\text { TApril 7-July 13, } 2014 \text { (14 weeks). } \\
\text { \#April 6-July 12, } 2015 \text { (14 weeks). }\end{array}$} \\
\hline
\end{tabular}

emergency in 2013 (11) and insight gained by the experience, the Ministry of Health and Medical Services rapidly established an EWARN to strengthen disease detection and response capabilities. We report an increase in diarrheal cases shortly after the floods, and despite implementation of control measures, large outbreaks were detected in the flood-affected areas of Honiara and other parts of Guadalcanal. We subsequently identified outbreaks in multiple areas not affected by the flooding, indicating transmission from flood to non-flood affected areas.

Several factors suggest rotavirus was prevalent during the outbreak. The proportion of rotavirus-positive samples was 38\% during 7 April-13 July, 2014, versus 0\% during the same period in 2013, and increased to 55\% during the peak of the outbreak from April 28-May 11. Outbreaks in non-flood affected provinces began soon after the peak of rotavirus transmission in Honiara. Illness and deaths caused by rotaviruses primarily affect the $<5$ years age group, unlike most other diarrheal agents with epidemic potential that affect all age groups (e.g., Vibrio cholerae, Shigella dysenteriae, norovirus) (12). Finally, all 4 isolates from 4 non-affected provinces demonstrated $100 \%$ genetic homology of target genes, consistent with a common origin.

\begin{tabular}{|c|c|c|c|}
\hline \multirow[b]{2}{*}{ Age group } & \multicolumn{2}{|c|}{ \% Positive (no. positive/no. tested) } & \multirow[b]{2}{*}{$p$ value§ } \\
\hline & $2013+$ & $2014 \ddagger$ & \\
\hline$<5 y$ & $0(0 / 12)$ & $41.9(18 / 43)$ & 0.005 \\
\hline$\geq 5 \mathrm{y}$ & $0(0 / 31)$ & $23.5(4 / 17)$ & 0.012 \\
\hline Unknown & NA & $100(1 / 1)$ & NA \\
\hline Total & $0(0 / 43)$ & $37.7(23 / 61)$ & $<0.001$ \\
\hline \multicolumn{4}{|c|}{$\begin{array}{l}\text { *Samples were collected and tested at the National Referral Hospital, } \\
\text { Honiara; no rotavirus tests were conducted during the outbreak period in } \\
\text { 2015. NA, not available. } \\
\text { †April 8-July 14, } 2013 \text { (14 weeks). } \\
\text { †April 7-July 13, } 2014 \text { (14 weeks). } \\
\text { §By Fisher exact test. }\end{array}$} \\
\hline
\end{tabular}

However, the small number of diarrheal samples tested for a small number of pathogens limited our ability to conclusively define the role of rotavirus versus other diarrheal pathogens. There was limited historical baseline data against which to compare our findings, but given the consistent collection of data through the PSSS during 2013-15, and the direct observations of multiple study authors (who were involved in outbreak response activities) of substantial surges in diarrhea cases throughout the country, we are confident that this was an outbreak and not seasonal fluctuation. We only included ambulatory cases and did not evaluate hospitalizations.

Improved understanding of the health implications of changing climate patterns is necessary to drive evidence-based mitigation strategies. Post-disaster early warning alert and response networks can ensure the rapid detection of, and response to, disease outbreaks that are likely to increase as climate change leads to more severe extreme weather events. Countries at risk for extreme weather events and other disasters, including many Pacific island nations, should ensure protocols and plans have been tested and are in place and to rapidly enhance disease detection and response capacities. Rotavirus may cause or contribute to epidemics in the post-disaster setting, emphasizing the importance of implementing global childhood rotavirus immunization guidelines (13).

\section{Acknowledgments}

Support for the study was provided by the Wilbur G. Downs Fellowship, the Coca-Cola World Fund at Yale University, and National Institutes of Health (R01 TW009504).We would like to thank Lavoni Tavoto, Adrian Simbe, the National Referral Hospital Laboratory, the Solomon Islands Red Cross, and Médecins Sans Frontières for providing assistance with data collection and analysis. We also thank Virginia Pitzer, Jordan Emont, Aref Senno, Georgiana Green, and Soledad Colombe for 


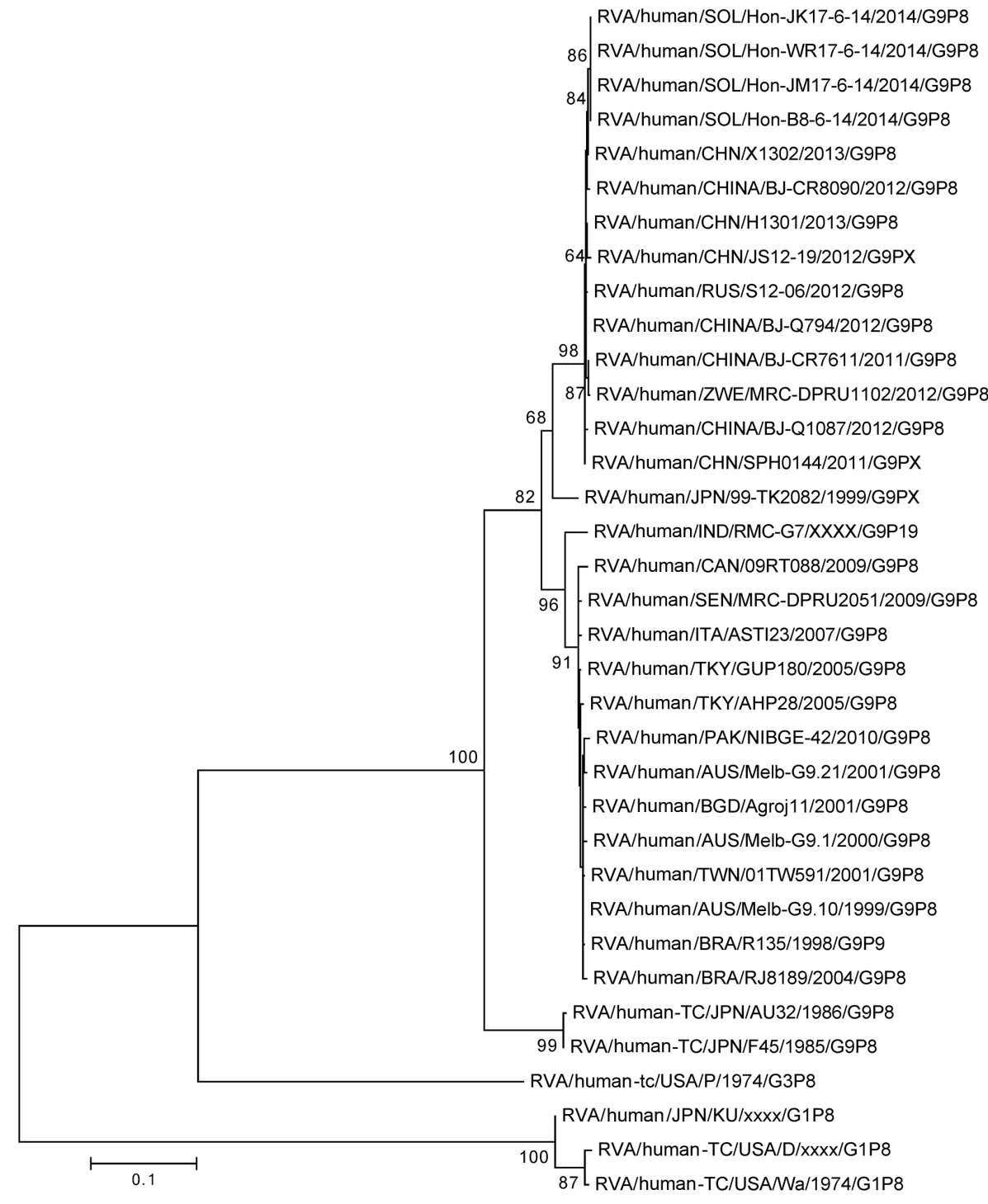

Figure 2. Nucleotide sequencebased phylogenetic tree of rotavirus viral protein (VP) 7 for isolates obtained in the Solomon Islands during an outbreak of diarrheal illness after flooding in the capital city of Honiara. Four isolates from different provinces had homologous VP7 sequences. We visually analyzed generated electropherograms and constructed contiguous DNA sequence files using the Sequencher Software program version 5.0.1 (Gene Codes Corp Inc., Ann Arbor, MI, USA). We performed nucleotide similarity searches using the BLAST (http://www.ncbi.nlm.nih.gov) and compared the nucleotide and deduced amino acid sequences of the VP7 gene with sequences available in GenBank possessing the entire open reading frame. We constructed multiple nucleotide and amino acid alignments using the MUSCLE algorithm in MEGA 6.0 (http://www.megasoftware. net/). Nucleotide and amino acid distance matrices were calculated by using the $p$-distance algorithm in MEGA 6.0. We selected the optimal evolutionary model based on the Akaike information criterion (corrected) ranking implemented in jModelTest (GitHub, Heidelberg, Germany) and generated maximumlikelihood phylogenetic trees using the nucleotide substitution model TrN+Gamma 4+I in MEGA 6.0, and assessed the robustness of branches by bootstrap analysis using 1,000 pseudoreplicate runs. Scale bar indicates base substitutions per site. their valuable insights on study design, analysis and revision and Losalini Vakasavuwaqa for administrative support.

The research at MCRI was supported by the Victorian Government's Operational Infrastructure Support Program. C.D. Kirkwood is director of Australian Rotavirus Surveillance Program and WHO Rotavirus Regional Reference laboratory and Collaborating Centre for Health (Rotavirus).

This investigation was exempted from approval by Solomon Islands and Yale University research review boards.

Mr. Jones is an Association of Schools and Programs of Public Health/CDC Allan Rosenfield Global Health Epidemiology Fellow in Dar es Salaam, Tanzania. His research interests include climate change, outbreak investigation, surveillance, and mathematical modeling.

\section{References}

1. Pachauri RK, Meyer LA, editors. Climate Change 2014: Synthesis Report. Contribution of working groups I, II and III to the fifth assessment report of the Intergovernmental Panel on Climate Change. IPCC. Geneva, Switzerland; 2014 [cited 2016 Jan 22]. https://www.ipcc.ch/report/ar5/syr/

2. Coumou D, Rahmstorf S. A decade of weather extremes. Nat Clim Chang. 2012;25:491-6 10.1038/nclimate1452.http://dx.doi.org/ 10.1038 /nclimate 1452

3. Watson JT, Gayer M, Connolly MA. Epidemics after natural disasters. Emerg Infect Dis. 2007;13:1-5._http://dx.doi.org/10.3201/ eid1301.060779

4. Cann KF, Thomas DR, Salmon RL, Wyn-Jones AP, Kay D. Extreme water-related weather events and waterborne disease. Epidemiol Infect. 2013;141:671-86. http://dx.doi.org/10.1017/ S0950268812001653

5. Office for the Coordination of Humanitarian Affairs Regional Office for the Pacific. Solomon Islands: flash floods situation report no. 4 (as of 18 April 2014). United Nations, 2014 [cited 2016 
Mar 7]. http://reliefweb.int/report/solomon-islands/solomonislands-flash-floods-situation-report-no-4-18-april-2014

6. National Oceanic and Atmospheric Administration. Global surface summary of the day-GSOD [cited 2015 Apr 26]. http://gis.ncdc.noaa.gov/geoportal/catalog/search/resource/details.jsp?id=gov.noaa.ncdc:C00516\# collapseOne

7. Kool JL, Paterson B, Pavlin BI, Durrheim D, Musto J, Kolbe A. Pacific-wide simplified syndromic surveillance for early warning of outbreaks. Glob Public Health. 2012;7:670-81. http://dx.doi.org/ 10.1080/17441692.2012.699536

8. World Health Organization. Outbreak surveillance and response in humanitarian emergencies: WHO guidelines for EWARN implementation. Geneva: The Organization; 2012 [cited 2016 Jan 22]. http://www.who.int/diseasecontrol_emergencies/publications/ who hse epr dce 2012.1/en/index.html

9. Kim J, Kim HS, Kim H-S, Kim J-S, Song W, Lee KM, et al. Evaluation of an immunochromatographic assay for the rapid and simultaneous detection of rotavirus and adenovirus in stool samples. Ann Lab Med. 2014;34:216-22. http://dx.doi.org/ 10.3343/alm.2014.34.3.216

10. Cowley D, Donato CM, Roczo-Farkas S, Kirkwood CD. Novel G10P[14] rotavirus strain, Northern Territory, Australia. Emerg Infect Dis. 2013;19:1324-7. PubMed http://dx.doi.org/10.3201/ eid1908.121653

11. Bilve A, Nogareda F, Joshua C, Ross L, Betcha C, Durski K, et al. Establishing an early warning alert and response network following the Solomon Islands tsunami in 2013. Bull World Health Organ. 2014;92:844-8 and. http://dx.doi.org/10.2471/BLT.13.133512

12. Black RE. Diarrheal diseases and child morbidity and mortality. Pop Dev Rev. 1984;10:141-61.

13. World Health Organization. Rotavirus vaccines: WHO position paper-January 2013. Wkly Epidemiol Rec. 2013;88:49-64

Address for correspondence: Eric J. Nilles, Emerging Disease

Surveillance \& Response, World Health Organization, Division of Pacific Technical Support, PO Box 113, Suva, Fiji; email: nillese@who.int

\section{January 2016: Sexually Transmitted Infections}

- Epidemiology of Haemophilus ducreyi Infections

\section{Including:}

- Waterborne Elizabethkingia meningoseptica in Adult Critical Care

- Human Papillomavirus Vaccination at a Time of Changing Sexual Behavior

- Multiorgan WU Polyomavirus Infection in Bone Marrow Transplant Recipient

- Multifacility Outbreak of Middle East Respiratory Syndrome in Taif, Saudi Arabia

- Falling Plasmodium knowlesi Malaria Death Rate among Adults despite Rising Incidence, Sabah, Malaysia, 2010-2014

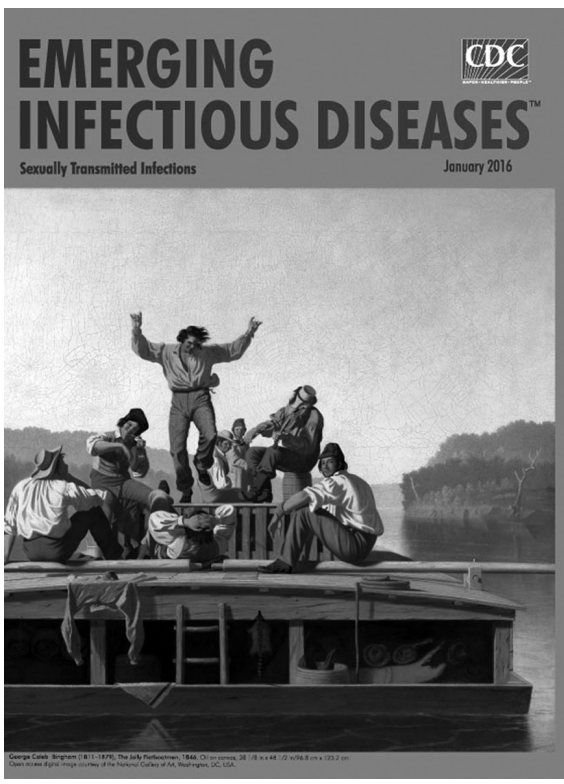

- Human Papillomavirus Prevalence and Herd Immunity after Introduction of Vaccination Program, Scotland, 2009-2013

- Porcine Epidemic Diarrhea Virus and Discovery of a Recombinant Swine Enteric Coronavirus, Italy

- Increase in Sexually Transmitted Infections among Men Who Have Sex with Men, England, 2014

- Seroepidemiology of Human Enterovirus 71 Infection among Children, Cambodia

- Outbreak of Panton-Valentine Leukocidin-Associated Methicillin-Susceptible Staphylococcus aureus Infection in a Rugby Team, France, 2010-2011

- Asymptomatic Lymphogranuloma Venereum in Men who Have Sex with Men, United Kingdom

http://wwwnc.cdc.gov/eid/articles/issue/22/01/table-of-contents 